\title{
Preparation of PLGA microspheres loaded with 10-hydroxycamptothecin and arsenic trioxide and their treatment for rabbit hepatocellular carcinoma
}

\author{
Yumin Wu, Duanming Du, Juanping Chen, Chunlin Liu
}

\begin{abstract}
Objective. This study aims to study the preparation method of arsenic trioxide $\left(\mathrm{As}_{2} \mathrm{O}_{3}\right)$ polylactic-co-glyconlic acid (PLGA) microspheres and 10-hydroxycamptothecin (HCPT) PLGA microspheres and explore their therapeutic effects as embolic agents for VX2 hepatocellular carcinoma in rabbits.

Methods. $\mathrm{As}_{2} \mathrm{O}_{3}$ and HCPT PLGA microspheres were prepared by multiple emulsion solvent evaporation method. Scanning electron microscopy (SEM) and particle size distribution were used to analyze the morphology, the drug sustained release ability was observed by the release of microspheres in vitro. The rabbit model of VX2 hepatocellular carcinoma was established and the hepatocellular carcinoma was treated with combined microspheres. The therapeutic effects were detected by qPCR, western blotting, HE staining and immunohistochemical methods.

Results. The PLGA microspheres loaded with $\mathrm{As}_{2} \mathrm{O}_{3}$ and HCPT were successfully prepared by optimizing the ratio. The particle size was between 30 and $50 \mu \mathrm{m}$. In vitro release results showed that PLGA microspheres loaded with $\mathrm{As}_{2} \mathrm{O}_{3}$ released completely in 10 days and PLGA microspheres loaded with HCPT released completely in 12 days. Western blotting and qPCR results showed that the expression of ALDH1A1 and Nanog decreased significantly in treatment group. HE staining and immunohistochemical analysis showed that the expression of CD31, HIF and VEGF decreased significantly and the apoptosis of tissues was obvious.

Conclusion. The combination of $\mathrm{As}_{2} \mathrm{O}_{3}$ and HCPT PLGA microspheres as embolization for VX2 hepatocellular carcinoma in rabbits has significant therapeutic effect.
\end{abstract}

Key words: polylactic-co-glyconlic acid (PLGA), arsenic trioxide $\left(\mathrm{As}_{2} \mathrm{O}_{3}\right)$, 10-hydroxycamptothecin (HCPT), western blotting; Immunohistochemistry

Received: September 27, 2019; Revised: December 2, 2019; Accepted: December 17, 2019; Available online: January 6, 2020 https://doi.org/10.5507/bp.2019.063

(c) 2021 The Authors; https://creativecommons.org/licenses/by/4.0/

Department of Interventional Therapy, Shenzhen Second People's Hospital. No. 3002 Sungang West Road, Futian District, Shenzhen, Guangdong 518035, P.R.China

Corresponding author: Yumin Wu, e-mail:wuyuming0878@163.com

\section{INTRODUCTION}

Primary liver cancer is one of the most common malignant tumors. Surgical resection is usually used in the early stage, but most patients with liver cancer are in the middle and advanced stage when they are diagnosed. At this time, non-surgical therapy is generally used ${ }^{1,2}$. Drug chemotherapy is a routine treatment for hepatocellular carcinoma. Many anticancer drugs have significant inhibitory effects on hepatocellular carcinoma cells, but they are easy to spread and have strong side effects on normal tissues, which limiting the development and application of drug therapy for hepatocellular carcinoma ${ }^{3,4}$.

Arsenic trioxide $\left(\mathrm{As}_{2} \mathrm{O}_{3}\right)$ was first used as an adjuvant drug in the treatment of malaria, tuberculosis and syphilis, it was later used in the treatment of acute promyelocytic leukemia and achieved certain therapeutic effects. Then it was found that $\mathrm{As}_{2} \mathrm{O}_{3}$ could also inhibit hepatocellular carcinoma and lung cancer, and $\mathrm{As}_{2} \mathrm{O}_{3}$ injection was developed for clinical treatment ${ }^{5}$. However, there are also many problems. Firstly, $\mathrm{As}_{2} \mathrm{O}_{3}$ has strong toxicity and side effects, it can kill tumor cells and damage normal cells at the same time. Secondly, $\mathrm{As}_{2} \mathrm{O}_{3}$ is less water-soluble and easy to precipitate when administered ${ }^{6}$. Hydroxycamptothecin (HCPT) is a kind of alkaloids extracted from plants with anti-cancer effect. Its disadvantage is that it is insoluble in water and slightly soluble in most organic solvents with short half-life. At present, the forms used in clinic are sodium salt injection, powder injection and capsule, but it is easy to oxidize and hydrolyze when exposed to light and heat, its curative effect is low?

In order to overcome these shortcomings, we developed a new treatment technology of hepatic artery embolization of hepatocellular carcinoma using polylactic-co-glyconlic acid (PLGA) microspheres as drug carriers to embolize $\mathrm{As}_{2} \mathrm{O}_{3}$ and HCPT. PLGA has good biocompatibility and biodegradability. It can be metabolized by human body, and eventually degraded to $\mathrm{H}_{2} \mathrm{O}$ and $\mathrm{CO}_{2}$. PLGA is widely used in drug carrier research. PLGA has the advantages of protecting the embedding drug, targeting the lesion, controlling drug release, prolonging drug action time, reducing drug toxicity and irritation $^{8-10}$. Therefore, this study explored the preparation method of PLGA microspheres, and successfully embedded $\mathrm{As}_{2} \mathrm{O}_{3}$ and HCPT into PLGA microspheres. At the same time, the related characterization in vitro was car- 
ried out. Animal model of liver cancer was established. The therapeutic effect was tested by embolization of PLGA microspheres combined with $\mathrm{As}_{2} \mathrm{O}_{3}$ and HCPT, and the possible mechanisms were analyzed.

\section{MATERIALS AND METHODS}

\section{Experimental cells and animals}

VX2 Rabbit anaplastic epidermal squamous cell carcinoma cell line was purchased from Beijing Beina Biological Technology Co., Ltd (BNCC100757). The cells were cultured in DMEM-H medium containing 10\% FBS with $5 \% \mathrm{CO}_{2}$ at $37{ }^{\circ} \mathrm{C}$.

New Zealand rabbits were purchased Nanchang Longping Rabbit Industry Co., Ltd. They were maintained in a temperature controlled room $\left(18-22^{\circ} \mathrm{C}\right)$ with 12-hr light /dark cycles, eat and drink freely. All animal experiments were conducted according to Principles of Laboratory Animal Care (National Society for Medical Research). This study was audited and approved by Animal Ethics Committee of Shenzhen Second People's Hospital.

\section{Reagents and instruments}

PLGA (aladdin P133293); $\mathrm{As}_{2} \mathrm{O}_{3}$ (Beijing doubleaigrettes Pharmaceutical Co., Ltd, 20170701); 10-hydroxycamptothecin (Solarbio SH8220); PVA(aladdin P105126); Hematoxylin Stain (BOSTER AR11800-1); Eosin Y Staining Solution (BOSTER AR11800-2); Scott blue solution (Solarbio G1865); DMEM completely high sugar Medium (NanJing KeyGen Biotech Co.,Ltd. KGM12800S-500); Trypsin-EDTA digestive fluid (Solarbio T1300); Trizon Reagent(CW0580S, Beijing ComWin Biotech Co.,Ltd.);Ultrapure RNA extraction kit (CW0581M, Beijing ComWin Biotech Co.,Ltd.); HiFiScript cDNA synthesis Kit (CW2569M, Beijing ComWin Biotech Co.,Ltd.); UltraSYBR Mix(CW0957M, Beijing ComWin Biotech Co.,Ltd.); BCA Protein Assay kit (CW0014S, Beijing ComWin Biotech Co.,Ltd.);Mouse Monoclonal Anti- $\beta$ actin (TA09, Beijing ZSGB-BIO Co.,Ltd., 1:2000); Horseradish Enzyme Labeled Goat Anti-Rat IgG(H+L) (ZB-2305, Beijing ZSGB-BIO Co.,Ltd., 1:2000); Rabbit Polyclonal Anti-Nanog(bs-6552R, Bioss,1:1000); Rabbit Polyclonal Anti-ALDH1A1(bs-6509R, Bioss, 1:1000); Horseradish Enzyme Labeled Goat Anti-Rabbit $\operatorname{IgG}(\mathrm{H}+\mathrm{L})(\mathrm{ZB}-$ 2301, Beijing ZSGB-BIO Co.,Ltd., 1:2000); Freeze dryer (Shanghai Bilon Instrument Co.,Ltd., FD-1A-50); Rotary evaporator (Shandong Biobase Co.,Ltd., RE-501); homogenizer (Ningbo Scientz Biotechnology Co.,L td., S10); Ultraviolet-Visible Spectrophotometer (Shanghai mapada Instrument Co.,Ltd., UV-1600PC); Inductively Coupled Plasma Mass Spectrometer (ICP-MS) (PE corporation, USA, optima 8000); Laser particle size analyzer (Malvern Zetasizer nano zs90); Fluorescent cell imaging instrument (Bio-Rad ZOETM); fluorescent quantitative PCR instrument (CFX Connect ${ }^{\mathrm{TM}}$, Bio-Rad Shanhhai Laboratories); Protein vertical electrophoresis instrument (DYY-6C, Beijing 61 instrument factory); Ultra High Sensitivity
Chemiluminescence Imaging System (Chemi DocTM XRS+, Bio-Rad Shanhhai Laboratories).

\section{Preparation of PLGA microspheres loaded with $\mathrm{HCPT} / \mathrm{As}_{2} \mathrm{O}_{3}$}

$200 \mathrm{mg}$ PLGA was dissolved in $10 \mathrm{~mL}$ dichloromethane solution by multiple emulsion solvent evaporation method, $10 \mathrm{mg} \mathrm{As}_{2} \mathrm{O}_{3}$ or $10 \mathrm{mg}$ HCPT was added to the above solution, and the colostrum solution was formed by stirring $10 \mathrm{~s}$ at $5000 \mathrm{rpm}$ with a hand-held homogenizer. Quickly pour colostrum solution into $10 \mathrm{~mL} \mathrm{3 \%} \mathrm{PVA,}$ stir $10000 \mathrm{rpm}$ under ice bath for $10 \mathrm{~s}$ to form multiple emulsion solution.

The multiple emulsion solution was poured into $500 \mathrm{~mL} 0.5 \%$ PVA, stirred by magnetic force for $2 \mathrm{~h}$ at room temperature and distilled by vacuum distillation for $6 \mathrm{~h}$ to remove residual organic solvents. They were centrifuged at $5000 \mathrm{rpm}$ for $15 \mathrm{~min}$ and washed with deionized water for three times, PLGA microspheres powder loaded $\mathrm{HCPT}$ or $\mathrm{As}_{2} \mathrm{O}_{3}$ can be obtained by freeze-drying precipitation. They were stored at $4{ }^{\circ} \mathrm{C}$. The blank PLGA microsphere powder can be prepared using the same method without adding drugs.

\section{Particle size determination of PLGA microspheres loaded with $\mathrm{HCPT} / \mathrm{As}_{2} \mathrm{O}_{3}$}

PLGA microspheres (or PLGA microspheres loaded with $\mathrm{HCPT} / \mathrm{As}_{2} \mathrm{O}_{3}$ ) were weighed and dissolved in water containing $0.5 \%$ Tween 80 to make the concentration of PLGA microspheres $1 \mathrm{mg} / \mathrm{mL}$. The particle size was determined by laser particle size analyzer immediately after ultrasonic dispersion for $10 \mathrm{~min}$.

\section{Release of PLGA microspheres loaded with HCPT/ $\mathrm{As}_{2} \mathrm{O}_{3}$ in vitro}

PLGA microspheres loaded with As2O3 were dissolved in $3 \mathrm{~mL}$ PBS and mixed, PLGA microspheres loaded with HCPT were dissolved in PBS containing 0.5\% Tween 80 and mixed, they shield from light with silver paper. They were cultured at $37^{\circ} \mathrm{C}$ with shaking at $200 \mathrm{rpm}$. The supernatants were collected every $24 \mathrm{~h}$ continuously for 12 consecutive days and stored at $4{ }^{\circ} \mathrm{C}$ after they were centrifuged for $5 \mathrm{~min}$ at $3000 \mathrm{r} / \mathrm{min}$. After continuous sampling, HCPT concentration was determined by ultraviolet spectrophotometer and standard curve was drawn. According to the standard curve, the release amount was determined and the release curve was drawn. $\mathrm{As}_{2} \mathrm{O}_{3}$ was determined by inductively coupled plasma mass spectrometry (ICP-MS), and the release curve was drawn.

\section{Establishment of rabbit liver cancer model}

VX2 Rabbit anaplastic epidermal squamous cell carcinoma cells in good condition were inoculated in the right hind leg of New Zealand rabbits and the tumors were formed after 1-2 weeks. The tumors were removed and cut into 2-3 $\mathrm{mm}^{3}$ size granules. The rabbits were anaesthetized and opened about $2 \mathrm{~cm}$ below the xiphoid process, the liver exposed to visual field. Tumor granules were clamped with microforceps and embedded in the liver about $1 \mathrm{~cm}$ deep. The abdominal cavity should be closed 
Table 1. Primers used in this study.

\begin{tabular}{llccc}
\hline Primer name & Primer sequence $\left(5^{\prime}-3^{\prime}\right)$ & Primer length $(\mathrm{bp})$ & Product length $(\mathrm{bp})$ & Annealing temperature $\left({ }^{\circ} \mathrm{C}\right)$ \\
\hline Nanog F & CCAGCCTCCTGAACCTTAGC & 20 & 122 & 60.2 \\
Nanog R & GCACCCCTGAGTCACACTG & 19 & & 59.1 \\
Aldh1a1 F & CGTTTGCTCCCTGCTATGTG & 20 & 225 & 59.6 \\
Aldh1a1 R & CGTGCTCTGCAGTTATCGTC & 20 & 210 & \\
$\beta$-actin F & TCTCGACGAAACCTAACGGC & 20 & & \\
$\beta$-actin R & CAATCAAAGTCCTCGGCCAC & 20 & & \\
\hline
\end{tabular}

and sutured until the liver is free of tumors and bleeding. The rabbits were randomly divided into Control group (Pseudo-embolization with normal saline), Empty group (Embolization with empty microspheres), Iodipin group (Embolization with lipiodol), $\mathrm{As}_{2} \mathrm{O}_{3}$ group (Embolization with PLGA microspheres loaded with $\mathrm{As}_{2} \mathrm{O}_{3}$ ), HCPT group (Embolization with PLGA microspheres loaded with $\mathrm{HCPT}$ ), $\mathrm{As}_{2} \mathrm{O}_{3}+\mathrm{HCPT}$ group (Embolization with PLGA microspheres loaded with $\left.\mathrm{As}_{2} \mathrm{O}_{3}+\mathrm{HCPT}\right)$.

\section{qRT-PCR}

Tissue samples were ground to powder in a mortar under liquid nitrogen. Total RNA was extracted using using a Trizol reagent kit (Invitrogen, Carlsbad, CA, USA) according to the manufacturer's protocol. RNA concentration and purity were detected using a Qubit Fluorometer (Thermo Fisher Scientific, Inc.). A total of $1 \mu \mathrm{g}$ RNA was subjected to reverse transcription using a Prime Script Kit (Takara Bio Inc., Otsu, Japan). qPCR was performed using a SYBR Premix Ex Taq ${ }^{\mathrm{TM}} \mathrm{Kit}$ (Takara Bio Inc.). The quantification method used was the 2- $\Delta \Delta \mathrm{CT}$ method. The thermocycling conditions were as follows: Pre-degeneration at $95^{\circ} \mathrm{C}$ for $10 \mathrm{~min}$, followed by 40 cycles of $95{ }^{\circ} \mathrm{C}$ for $12 \mathrm{~s}$ and $62{ }^{\circ} \mathrm{C}$ for $40 \mathrm{sec}$, U6 and $\beta$-actin genes were used as an internal control. The primers used in this study are shown in Table 1.

\section{Western blotting test}

Total proteins were extracted and protein concentration was determined using BCA. Proteins (50 $\mu \mathrm{g}$ per lane) were separated using 12\% SDS-PAGE, then they were electrotransferred to a PVDF membrane (Amersham Biosciences, Piscataway, NJ, USA). The PVDF membrane was rinsed with TBS for $10-15 \mathrm{~min}$, placed in TBS/T blocking buffer containing $5 \%(\mathrm{w} / \mathrm{v})$ skimmed milk powder. It was incubated at room temperature for $2 \mathrm{~h}$ following the addition of an appropriate dilution of primary antibodies. The membrane was then rinsed with TBST three times (5-10 $\mathrm{min} /$ wash) and then incubated at room temperature for $1 \mathrm{~h}$ with horseradish peroxidase-labeled secondary antibody (1:50,000; Abcam, Cambridge, UK; diluted with TBST containing $0.05 \%(\mathrm{w} / \mathrm{v})$ skimmed milk powder). The membrane was then rinsed three times with TBST (5-10 min/wash). Protein bands were detected using an enhanced chemiluminescence kit (Perkin-Elmer Inc.) and quantified as the ratio to $\beta$-actin. Quantification was performed using Imagequant LAS4000 (GE Healthcare, Japan).

\section{HE staining test}

The tissues were taken and washed with PBS, then they were fixed with $4 \%$ paraformaldehyde solution and embedded in paraffin. They were cut into $5 \mu \mathrm{m}$ slices and stained with HE using conventional method. Briefly, Deparaffinize sections, 2 changes of xylene, 10 min each; Re-hydrate in 2 changes of absolute alcohol, 5 min each; 95\% alcohol for $2 \mathrm{~min}$ and $70 \%$ alcohol for $2 \mathrm{~min}$; Wash briefly in distilled water; Stain in Harris hematoxylin solution for $8 \mathrm{~min}$; Wash in running tap water for $5 \mathrm{~min}$; Differentiate in 1\% acid alcohol for $30 \mathrm{~s}$; Wash running tap water for $1 \mathrm{~min}$; Bluing in $0.2 \%$ ammonia water or saturated lithium carbonate solution for $30 \mathrm{~s}$ to $1 \mathrm{~min}$; Wash in running tap water for $5 \mathrm{~min}$; Rinse in 95\% alcohol, 10 dips; Counterstain in eosin-phloxine solution for 30 s to 1 min; Dehydrate through 95\% alcohol, 2 changes of absolute alcohol, 5 min each; Clear in 2 changes of xylene, 5 min each; Mount with xylene based mounting medium. They were observed under optical microscope.

\section{Immunohistochemical test}

Briefly, the tissues were embedded with paraffin using conventional method. They were cut into $5 \mu \mathrm{m}$ slices, and incubated with $0.3 \%$ endogenous peroxidase blocking solution for 20 min after dewaxing and hydrating. Then they were incubated at room temperature for 10 min with $3 \%$ hydrogen peroxide methanol solution, and washed with PBS for 3 times ( $3 \mathrm{~min} /$ time). Antigen retrieval was performed using citrate buffer $(\mathrm{pH}$ 6.0) at $121{ }^{\circ} \mathrm{C}$ for $2 \mathrm{~min}$. After blocking with 5\% BSA (Gibco; Thermo Fisher Scientific, Inc), they were incubated with a primary monoclonal antibody overnight at $4{ }^{\circ} \mathrm{C}$. They were then incubated with goat anti-rabbit non-biotinylated regents (Zhongshanjinqiao, Beijing, China) according to the manual and mounted with epoxy resin. They were observed using Photo and Image Auto Analysis System (Image-Pro-Plus, China). Five visual fields were randomly selected for each slice.

\section{Statistical analysis}

The data were analyzed using SPSS 19.0 software (SPSS Inc., Chicago, IL, USA). All results are presented as the mean \pm standard deviation (SD) and t-test were used for comparison between groups. $P<0.05$ was considered to indicate a statistically significant difference. 


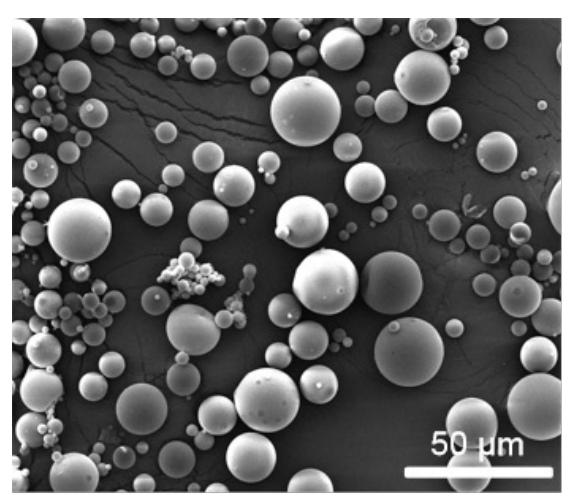

PLGA

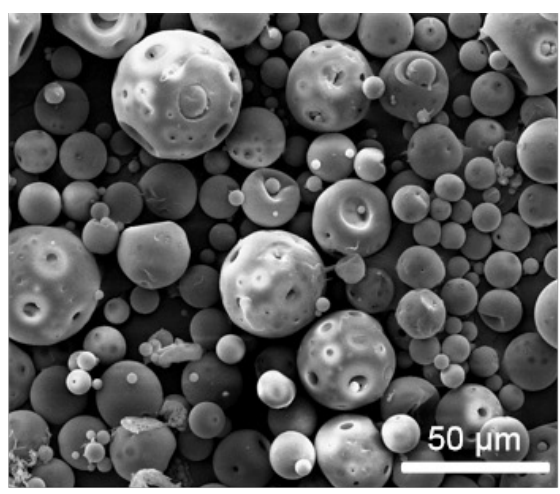

PLGA@As $\mathrm{O}_{3}$

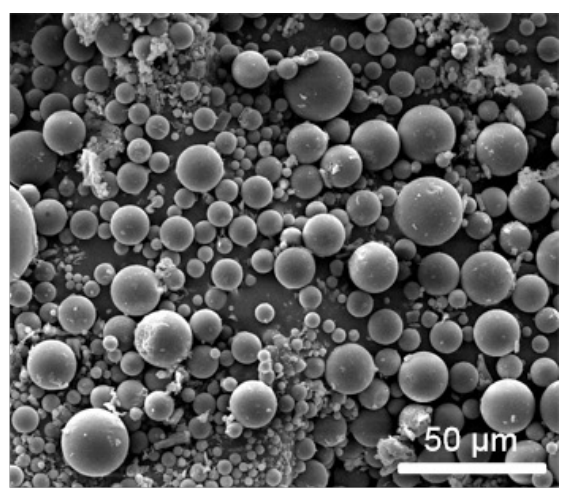

PLGA@HCPT
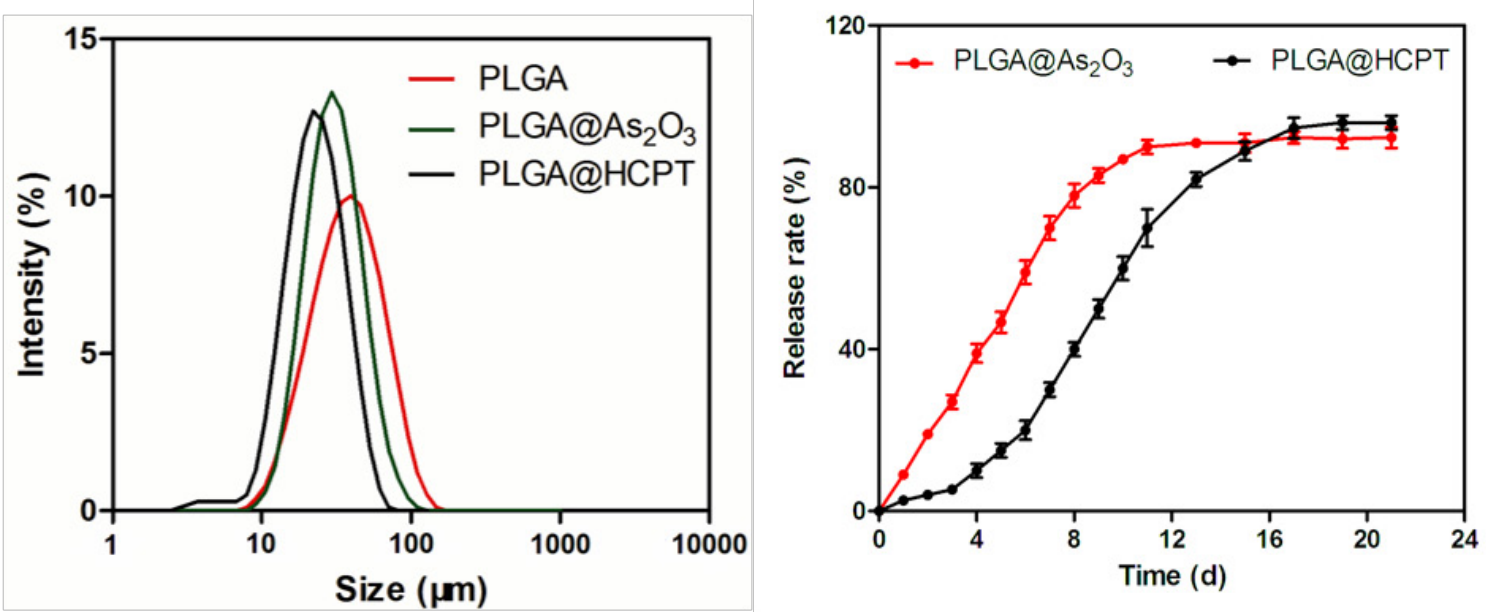

Fig. 1. Characterization and in vitro release of PLGA microspheres loaded with $\mathrm{HCPT} / \mathrm{As}_{2} \mathrm{O}_{3}$.

\section{RESULTS}

Characterization and in vitro release of PLGA microspheres loaded with $\mathrm{HCPT} / \mathrm{As}_{2} \mathrm{O}_{3}$

As shown in Fig. 1, the shape of HCPT/As ${ }_{2} \mathrm{O}_{3}$ PLGA microspheres and empty PLGA microspheres were uniform spherical, regular in size and shape. Only PLGA microspheres with $\mathrm{As}_{2} \mathrm{O}_{3}$ have some dents on the surface. The particle size distribution showed that the size of PLGA microspheres loaded with $\mathrm{HCPT} / \mathrm{As}_{2} \mathrm{O}_{3}$ ranged from 30 to $50 \mu \mathrm{m}$ and had no impurity peaks. PLGA microspheres loaded with $\mathrm{As}_{2} \mathrm{O}_{3}$ released rapidly and tended to release completely in 10 days, the PLGA microspheres loaded with HCPT tended to release completely in 12 days. Both of their respective release rates were above $90 \%$.

\section{ALDH1A1 and Nanog expression}

The expression levels of ALDH1A1 and Nanog in $\mathrm{HCPT}+\mathrm{As}_{2} \mathrm{O}_{3}$ PLGA microspheres group were significantly lower than that in control group and single administration group, and the difference was significant (Fig. 2, $P<0.05)$.
HE staining results of the effects of combined embolization of PLGA microspheres loaded with $\mathrm{HCPT}$ and $\mathrm{As}_{2} \mathrm{O}_{3}$ on liver tissues

As shown in Fig. 3, the HCC cells grew densely and ovally without necrosis or decay in Control group and Empty group. Large area of cell necrosis and apoptosis were observed in Iodipin group, $\mathrm{As}_{2} \mathrm{O}_{3}$ group and HCPT group. The apoptosis of HCC was more obvious, with nucleus cleavage and large area necrosis in $\mathrm{As}_{2} \mathrm{O}_{3}+\mathrm{HCPT}$ group. These results suggested that combined embolization had significant inhibitory effect on HCC cells.

Immunohistochemical results of the effects of combined embolization of PLGA microspheres loaded with HCPT and $\mathrm{As}_{2} \mathrm{O}_{3}$ on CD31, HIF and VEGF expression

The immunohistochemical results showed that CD31, HIF and VEGF expression levels significantly decreased in Iodipin group, $\mathrm{As}_{2} \mathrm{O}_{3}$ group, HCPT group and $\mathrm{As}_{2} \mathrm{O}_{3}+\mathrm{HCPT}$ group compared with that of control group (Fig. 4). The decline was more obvious at the 14th day. The results suggested that the HCC was controlled and the disease was alleviated after microsphere embolization.

\section{DISCUSSION}

As a new embolic agent, drug-loaded sustained-release microspheres have good drug treatment and block- 


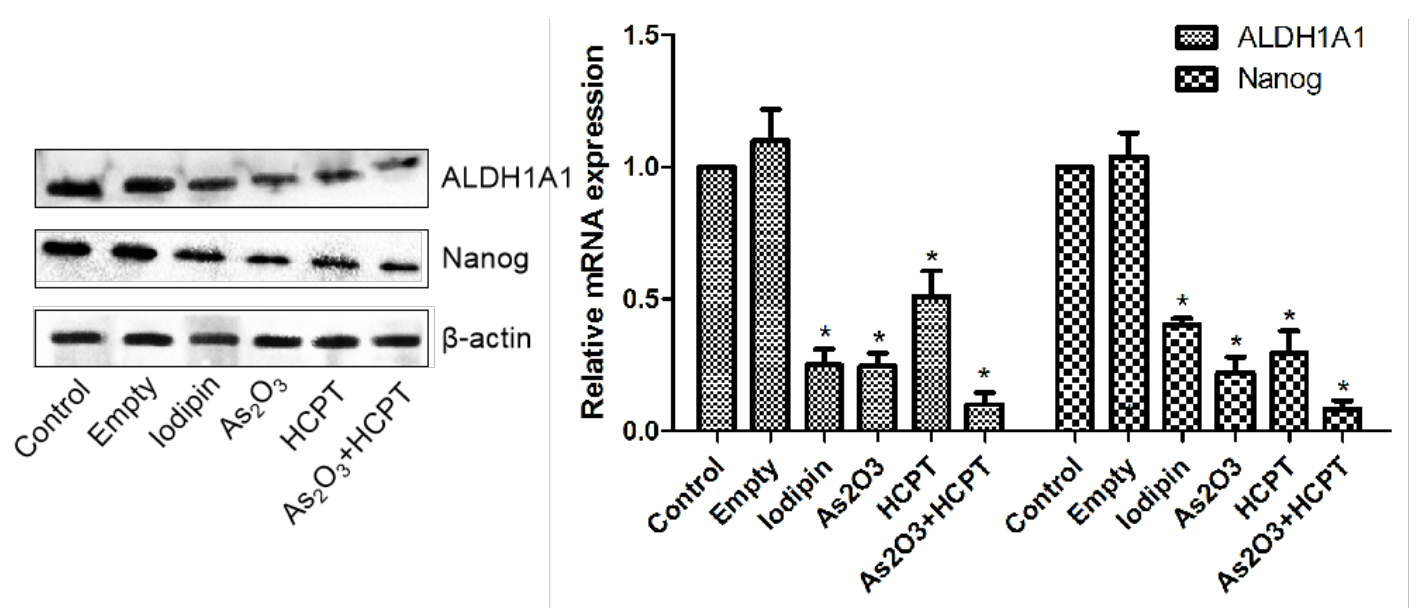

Fig. 2. ALDH1A1 and Nanog expression levels in different groups ( ${ }^{*} P<0.05$ vs. Control).

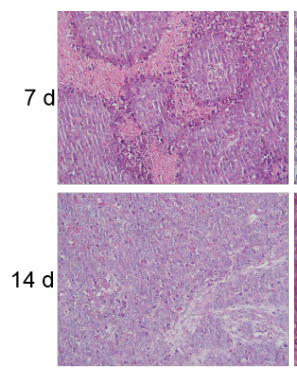

Control
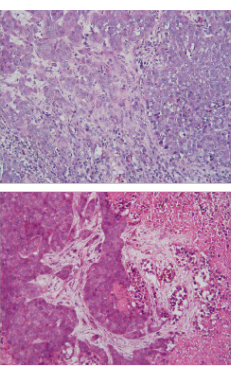

Empty
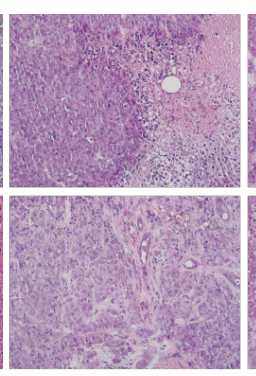

lodipin
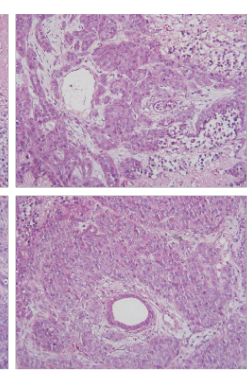

$\mathrm{As}_{2} \mathrm{O}_{3}$

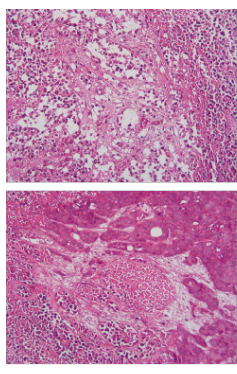

HCPT

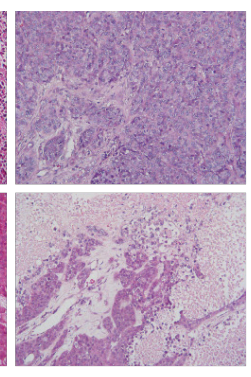

$\mathrm{As}_{2} \mathrm{O}_{3}+\mathrm{HCPT}$

Fig. 3. HE staining detection of the effects of combined embolization of PLGA microspheres loaded with $\mathrm{HCPT}$ and $\mathrm{As}_{2} \mathrm{O}_{3}$ on liver tissues $(200 \times)$.

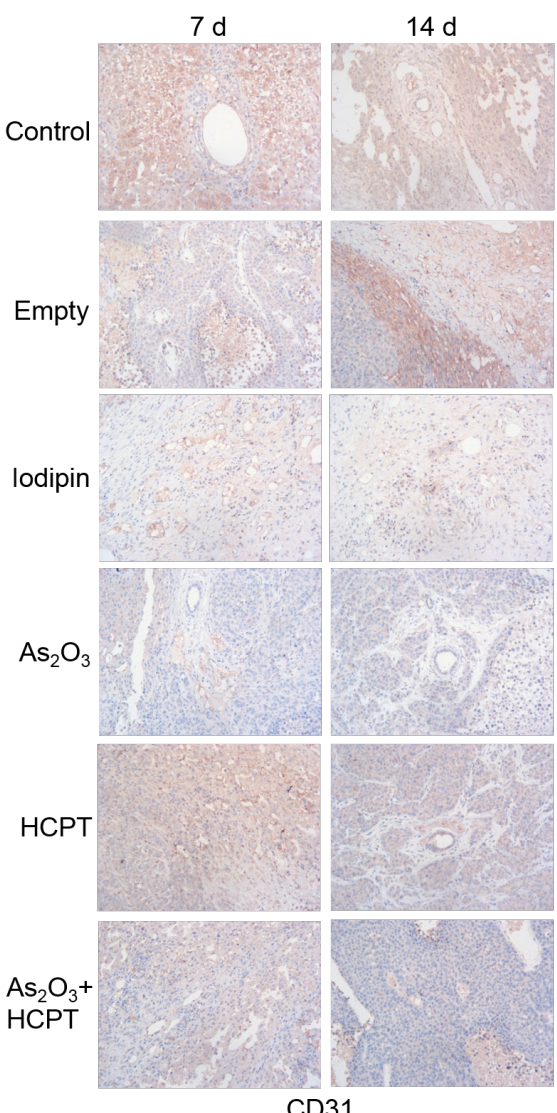

CD31
$7 \mathrm{~d}$
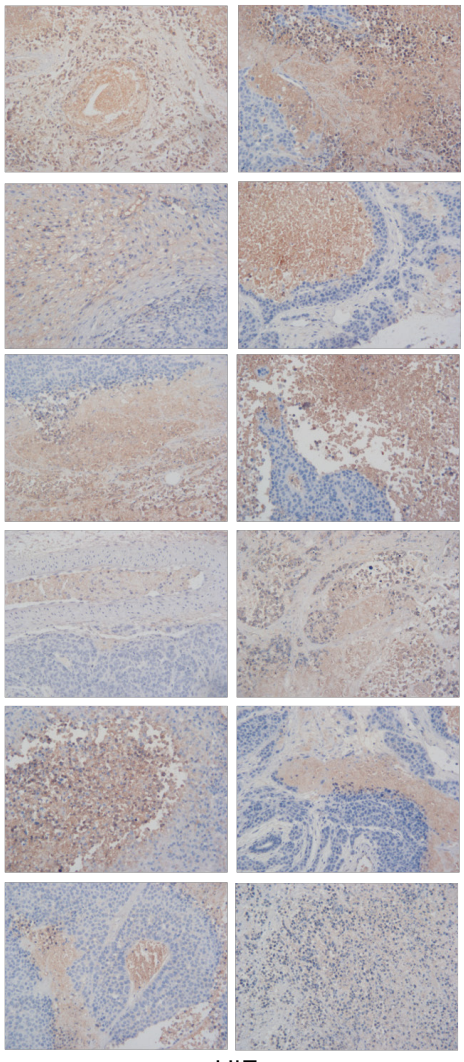

$14 \mathrm{~d}$
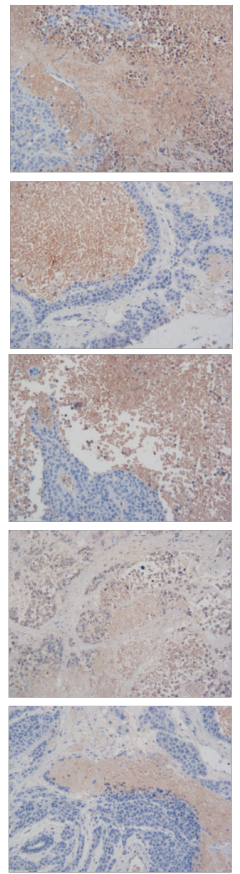

HIF
$7 \mathrm{~d}$
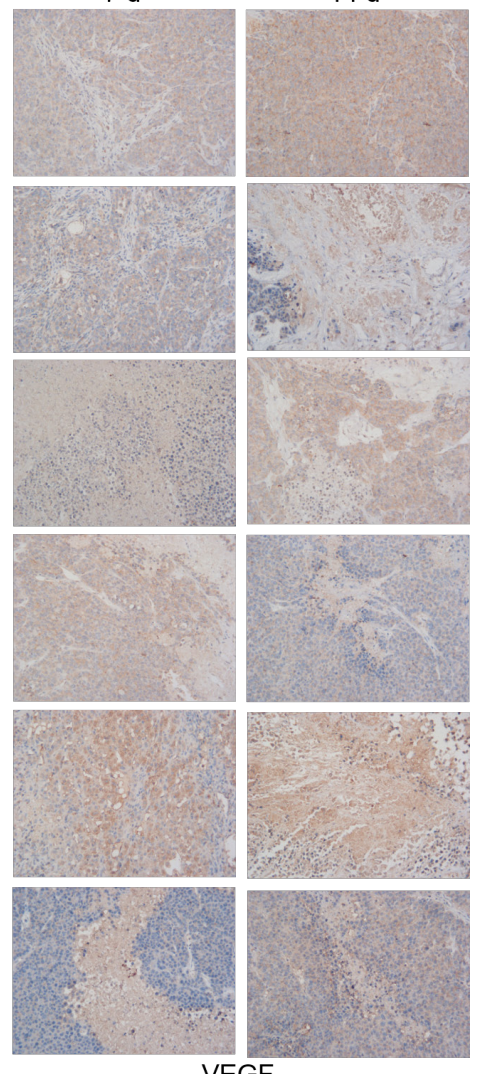

Fig. 4. Immunohistochemical detection of the effects of combined embolization of PLGA microspheres loaded with HCPT and $\mathrm{As}_{2} \mathrm{O}_{3}$ on CD31, HIF and VEGF expression $(200 \times)$. 
ing function of hepatic artery vessels, it has been widely used worldwide ${ }^{11,12}$. In this study, the characterization of $\mathrm{HCPT} / \mathrm{As}_{2} \mathrm{O}_{3}$ PLGA microspheres was detected by scanning electron microscopy. The results showed that the shape of $\mathrm{HCPT} / \mathrm{As}_{2} \mathrm{O}_{3}$ PLGA microspheres was not significantly different from that of PLGA microspheres without carrier. The particle size distribution showed that the microspheres were uniform and stable with good effect. There was no sudden or slow release and the process was smooth, which showed that PLGA microspheres had good drug carrier function.

Aldehyde dehydrogenases (ALDH1A1) A1 subtype is closely related to many kinds of cancers and overexpressed in cancer tissues ${ }^{13}$. Nanog expression in differentiated cells gradually decreased or lost, but it was abnormally activated and overexpressed in cancer cells. Nanog participated in the growth, metastasis and drug resistance of tumors by regulating the proliferation, migration and invasion of tumors, the dry nature of tumors and the immune escape of tumors ${ }^{14,15}$. In this study, western blotting and qPCR results showed that the expression of ALDH1A1 and Nanog decreased significantly in the control group and the single drug group. The combination drugs may inhibit the growth of cancer cells by inhibiting the expression of ALDH1A1 and Nanog through sustained release of drugs. HE staining results also showed the effect of combined embolization drugs. CD31, HIF and VEGF are angiogenesis factors ${ }^{16-18}$. Neovascularization is one of the conditions for tumorigenesis. Hepatocellular carcinoma (HCC) is a multivessel tumor. Compared with traditional lipiodol embolization, drug-loaded microspheres embolization for HCC has the advantage of not only blocking the existing hepatic artery ${ }^{19}$, but also inhibiting the formation of new blood vessels by releasing drugs $\mathrm{As}_{2} \mathrm{O}_{3}$ and HCPT, which reduces the expression of CD31, HIF and VEGF.

It has been found that $\mathrm{As}_{2} \mathrm{O}_{3}$ can affect cell cycle, inhibit the proliferation and migration of cancer cells, and induce apoptosis of cancer cells. $\mathrm{As}_{2} \mathrm{O}_{3}$ can promote the apoptosis of tumor vascular endothelial cells, interfere with the interaction between endothelial cells and tumor cells, thus inducing endothelial cell apoptosis, inhibiting tumor angiogenesis, and indirectly inhibiting tumor growth $^{20,21}$. HCPT mainly forms ternary complexes with DNA and topoisomerase I, inhibits angiogenesis, blockades DNA replication and leads to cell death, thus showing anti-tumor activity. HCPT acts on $\mathrm{S}$ phase of cell cycle and is a cell cycle specific drug. It can inhibit mitosis at high concentration and prevent cells from entering the mitotic phase ${ }^{22}$. Researchers who have different opinions on the mechanism of the two drugs for HCC have not formed a unified idea. In this study, we prefer that $\mathrm{As}_{2} \mathrm{O}_{3}$ and HCPT mainly act on blood vessel-related cells, inhibit the formation of new blood vessels and thus inhibit the growth of tumors.

The new PLGA drug-loaded microsphere embolization agent has incomparable advantages compared with traditional embolization agent, and has a broad application prospect in the treatment of HCC. This study provides a new choice for the application of drug-loaded microsphere embolization agent.
Acknowledgement: This study was supported by the Project of Shenzhen Science and Technology Founding Committee (JCYJ20150330102720120).

Author contributions: YW: conceived and designed the experiments; DD, JC: execution of experiments; YW, DD: data analysis; YW, DD, CL: discussion of results; YW, DD: wrote and or critical reading of manuscript.

Conflict of interest statement: The authors declare that they have no competing interests to disclose.

\section{REFERENCES}

1 Li HY, Wei YG, Yan LN, Li B. Salvage liver transplantation in the treatment of hepatocellular carcinoma: a meta-analysis. World J Gastroenterol 2012;18: 2415-22.

2 Kulik LM, Fisher RA, Rodrigo DR, Brown RS, Jr., Freise CE, Shaked A, Everhart JE, Everson GT, Hong JC, Hayashi PH, Berg CL, Lok AS, Group AAS. Outcomes of living and deceased donor liver transplant recipients with hepatocellular carcinoma: results of the A2ALL cohort. Am J Transplant 2012;12:2997-3007.

3 Wu GL, Zhang L, Li TY, Chen J, Yu GY, Li JP. Short-term effect of combined therapy with Jinlong Capsule and transcatheter arterial chemoembolization on patients with primary hepatic carcinoma and its influence on serum osteopontin expression. Chin J Integr Med 2010;16:109-13.

4 Park HC, Yu Jl, Cheng JC, Zeng ZC, Hong JH, Wang ML, Kim MS, Chi KH, Liang PC, Lee RC, Lau WY, Han KH, Chow PK, Seong J. Consensus for Radiotherapy in Hepatocellular Carcinoma from The 5th AsiaPacific Primary Liver Cancer Expert Meeting (APPLE 2014): Current Practice and Future Clinical Trials. Liver Cancer 2016;5:162-74.

5 You BR, Park WH. Arsenic trioxide induces human pulmonary fibroblast cell death via increasing ROS levels and GSH depletion. Oncol Rep 2012;28:749-57.

6 Wen X, Li D, Zhang Y, Liu S, Ghali L, Iles RK. Arsenic trioxide induces cervical cancer apoptosis, but specifically targets human papillomavirus-infected cell populations. Anticancer Drugs 2012;23:280-7.

7 Qin LZ, Zhang X, Wu LN, Zhang J, Pan X, Li G and Wu CB. Preparation and in vitro embolic efficiency evaluation of hydroxycamptothecineloaded liquid embolic agent. Yao Xue Xue Bao 2014; 49: 1069-1075.

8 Wang T, Zhang C, Zhong W, Yang X, Wang A, Liang R. Modification of Three-Phase Drug Release Mode of Octreotide PLGA Microspheres by Microsphere-Gel Composite System. AAPS Pharm Sci Tech 2019;20(6):228.

9 Andhariya JV, Shen J, Wang Y, Choi S, Burgess DJ. Effect of minor manufacturing changes on stability of compositionally equivalent PLGAmicrospheres. Int J Pharm 2019;566:532-40.

10 Li S, Liu J, Li G, Zhang X, Xu F, Fu Z, Teng L, Li Y, Sun F. Near-infrared light-responsive, pramipexole-loaded biodegradable PLGA microspheres for therapeutic use in Parkinson's disease. Eur J Pharm Biopharm 2019;141:1-11.

11 Huang G, Lai EC, Lau WY, Zhou WP, Shen F, Pan ZY, Fu SY, Wu MC. Posthepatectomy HBV reactivation in hepatitis B-related hepatocellular carcinoma influences postoperative survival in patients with preoperative low HBV-DNA levels. Ann Surg 2013;257:490-505.

12 Nomoto S, Kanda M, Okamura Y, Nishikawa Y, Qiyong L, Fujii T, Sugimoto $\mathrm{H}$, Takeda S, Nakao A. Epidermal growth factor-containing fibulin-like extracellular matrix protein 1, EFEMP1, a novel tumorsuppressor gene detected in hepatocellular carcinoma using double combination array analysis. Ann Surg Oncol 2010;17:923-32.

13 Miyata T, Oyama T, Yoshimatsu T, Higa H, Kawano D, Sekimura A, Yamashita N, So T, Gotoh A. The Clinical Significance of Cancer Stem Cell Markers ALDH1A1 and CD133 in Lung Adenocarcinoma. Anticancer Res 2017;37:2541-7.

14 Do DV, Ueda J, Messerschmidt DM, Lorthongpanich C, Zhou Y, Feng B, Guo G, Lin PJ, Hossain MZ, Zhang W, Moh A, Wu Q, Robson P, Ng $\mathrm{HH}$, Poellinger L, Knowles BB, Solter D, Fu XY. A genetic and developmental pathway from STAT3 to the OCT4-NANOG circuit is essential for maintenance of ICM lineages in vivo. Genes Dev 2013;27:137890.

15 Hyslop L, Stojkovic M, Armstrong L, Walter T, Stojkovic P, Przyborski S, Herbert M, Murdoch A, Strachan T, Lako M. Downregulation of 
NANOG induces differentiation of human embryonic stem cells to extraembryonic lineages. Stem Cells 2005;23:1035-43.

16 Tsoli E, Zacharatos P, Dasiou-Plakida D, Peros J, Evangelou K, Zavras Al, Yannoukakos D, Konstantopoulou I, Asimacopoulos PJ, Kittas C, Gorgoulis VG. Growth index is independent of microvessel density in non-small-cell lung carcinomas. Hum Pathol 2002;33:812-8.

17 Kitajima Y, Miyazaki K. The Critical Impact of HIF-1a on Gastric Cancer Biology. Cancers (Basel) 2013;5:15-26.

18 Clara CA, Marie SK, de Almeida JR, Wakamatsu A, Oba-Shinjo SM, Uno $M$, Neville $M$, Rosemberg $S$. Angiogenesis and expression of PDGF-C, VEGF, CD105 and HIF-1alpha in human glioblastoma. Neuropathology 2014;34:343-52.

19 Kettenbach J, Stadler A, Katzler IV, Schernthaner R, Blum M, Lammer J, Rand T. Drug-loaded microspheres for the treatment of liver cancer: review of current results. Cardiovasc Intervent Radiol 2008;31:468-76.

20 Zhang X, Jia S, Yang S, Yang Y, Yang T, Yang Y. Arsenic trioxide induces G2/M arrest in hepatocellular carcinoma cells by increasing the tumor suppressor PTEN expression. J Cell Biochem 2012;113:3528-35.

21 Fei M, Lu M, Wang Y, Zhao Y, He S, Gao S, Ke Q, Liu Y, Li P, Cui X, Shen A, Cheng C. Arsenic trioxide-induced growth arrest of human hepatocellular carcinoma cells involving FOXO3a expression and localization. Med Oncol 2009;26:178-85.

22 van der Zee AG, Hollema $\mathrm{H}$, de Jong S, Boonstra $\mathrm{H}$, Gouw A, Willemse PH, Zijlstra JG, de Vries EG. P-glycoprotein expression and DNA topoisomerase I and II activity in benign tumors of the ovary and in malignant tumors of the ovary, before and after platinum/cyclophosphamide chemotherapy. Cancer Res 1991;51:5915-20. 